\title{
Again about reliability characteristics of electrical power grids elements
}

\author{
Abdula Abdurakhmanov ${ }^{1}$, Sergey Glushkin ${ }^{1}$, Vladislav Plotnikov ${ }^{1}$, Andrey Shuntov ${ }^{1 *}$ \\ ${ }^{1}$ Moscow Power Engineering Institute, Department of Electric Power Systems, Krasnokazarmennaya 14, Moscow, \\ 111250 Russia.
}

\begin{abstract}
The reliability characteristics of the (auto)transformers and overhead transmission lines of the unified national electric grid are subjected to statistical analysis. It is shown that their scheduled outages for scheduled or unscheduled repairs, as well as maintenance, weaken the network layout much more than emergency repairs. At the same time, there was a noticeable deterioration in the (auto)transformers and overhead transmission line reliability indexes over the last 30 years, which requires the development and adoption of appropriate organizational and technical solutions.
\end{abstract}

\section{Problem description}

Problem of power systems reliability performance existed before and continue to be relevant. One of its aspects is traditionally a research of reliability indexes of electrical grids. The most important are: failure intensity (precisely - mean failure intensity or failure rate); mean restoration time; medium frequency $\mu$ and duration $T_{\text {rep }}$ of scheduled repairs.

Reliability characteristics of (auto)transformers ((A)T) and overhead power transmission lines (OHL) were analyzed in many published papers [1-6]. On it may be concluded that their fault characteristics are roughly the same, despite different time periods of monitoring: from 1980s-era till the beginning of 2000s. It is to be supposed that the reason is that equipment failures are investigated thoroughly followed by development of organizational-technical measures of their prevention.

In its turn the information about reliability characteristics of scheduled repairs is less presented and it's often controversial. Published data about characteristics of (A)T scheduled outages and singlecircuit and double-circuit OHL is shown in the Table 1; Metal OHL supports are taken as a basis, as the most commonly used.

Table 1. Reliability characteristics of (auto)transformers.

\begin{tabular}{|c|c|c|c|c|c|c|c|}
\hline \multirow{2}{*}{ Voltage, $\mathrm{kV}$} & \multicolumn{4}{|c|}{$\mu, 1 /$ year } & \multicolumn{3}{c|}{$T_{\text {rep }}, \mathrm{hrs}$} \\
\hline 110 & 0,5 & 1,0 & 6,3 & 3,2 & 28 & 30 & 10,5 \\
\hline 220 & 0,9 & 1,0 & 6,3 & 3,2 & 28 & 30 & 12,0 \\
\hline 330 & 1,0 & 1,0 & 6,3 & 3,2 & 30 & 30 & 12,8 \\
\hline 500 & 1,0 & 1,0 & 6,3 & 3,2 & 50 & 50 & 14,0 \\
\hline 750 & 1,0 & 1,0 & 6,3 & - & 50 & 50 & - \\
\hline Source & {$[1]$} & {$[2]$} & {$[3]$} & {$[4]$} & {$[1]$} & {$[2]$} & {$[3]$} \\
\hline
\end{tabular}

Thus, frequency of (A)T scheduled repairs in [1] and [2] is defined as $11 /$ year. It clearly says in [2], that it's periodicity of only current repairs. Therefore, medium and major repairs are left out of consideration. In [3] $\mu$ values are defined at a level of 6,3 1 /year with reference to [4]. However, in [4] there was talk of scheduled commutations, i.e. total bringing into and withdrawal from operation count, from where frequency of scheduled repairs $\mu=6,3 / 2 \approx 3,21 /$ year. As one can see, inconsistent information about (A)T scheduled outages is presented in considered sources.

Table 2. Reliability characteristics of single-circuit overhead lines.

\begin{tabular}{|c|c|c|c|c|c|c|c|c|c|}
\hline Voltage, $\mathrm{kV}$ & \multicolumn{3}{|c|}{$\mu, 1 /$ year } & \multicolumn{4}{c|}{$T_{\text {rep }}$, hrs } \\
\hline 110 & 2,9 & 2,1 & 15,0 & 7,2 & 2,7 & 14,9 & 14,5 & 4,2 & 15,2 \\
\hline 220 & 5,0 & 2,8 & 13,2 & 7,4 & 2,9 & 25,4 & 17,0 & 5,9 & 12,4 \\
\hline 330 & 5,7 & 3,0 & 12,0 & 5,2 & 2,4 & 20,1 & 21,0 & 7,9 & 14,3 \\
\hline 500 & 12,8 & 3,1 & 10,0 & 5,0 & 1,5 & 16,6 & 18,0 & 12,0 & 16,7 \\
\hline 750 & 10,0 & 0,17 & - & - & - & 9,6 & - & - & - \\
\hline Source & {$[1]$} & {$[2]$} & {$[3]$} & {$[4]$} & {$[5]$} & {$[1]$} & {$[2]$} & {$[3]$} & {$[5]$} \\
\hline
\end{tabular}

\footnotetext{
* Corresponding author sh280859@gmail.com
} 
Works [2, 5] should be recognized as works with the most significant statistical samples. A medium frequency of scheduled repairs of OHL $220-500 \mathrm{kV}$ in [5] vary (table 2) from 1.5 to 2.9 1/year; but in [2] it's within the range 2,8-3,1 1/year. Later works refers to much greater values: 10,0-13,2 [3] and 5,0-12,8 [1] 1/year. A medium frequency of scheduled OHL commutations is presented in [4], which equals 10,014,8 1/year, i.e. sum of their switching on/off; it is clear, that frequency of OHL scheduled repairs from [4] will be twice as little, i.e 5,0-7,4 1/year. It can be assumed, that such significant spread in presented characteristics can't give an estimate of real reliability characteristics of overhead lines in terms of scheduled outages.

Table 3. Reliability characteristics of double-circuit overhead lines.

\begin{tabular}{|c|c|c|c|c|c|}
\hline Voltage, $\mathrm{kV}$ & Downtime & \multicolumn{2}{|c|}{$\mu, 1 /$ year } & \multicolumn{2}{|c|}{$T_{\text {rep }}, \mathrm{hrs}$} \\
\hline \multirow{3}{*}{110} & $\begin{array}{c}\text { single } \\
\text { circuit }\end{array}$ & 3,8 & 3,2 & 14,8 & 14,8 \\
\cline { 2 - 6 } & $\begin{array}{c}\text { double } \\
\text { circuit }\end{array}$ & 0,4 & 0,17 & 19,0 & 21,8 \\
\hline \multirow{3}{*}{220} & $\begin{array}{c}\text { single } \\
\text { circuit }\end{array}$ & 3,3 & 3,36 & 17,4 & 11,9 \\
\cline { 2 - 6 } & $\begin{array}{c}\text { double } \\
\text { circuit }\end{array}$ & 0,5 & 0,08 & 24,0 & 24,2 \\
\hline \multirow{3}{*}{330} & $\begin{array}{c}\text { single } \\
\text { circuit }\end{array}$ & 7,3 & 7,11 & 15,0 & 9,4 \\
\cline { 2 - 6 } & $\begin{array}{c}\text { double } \\
\text { circuit }\end{array}$ & 0,3 & - & 14,1 & - \\
\hline Source & & {$[2]$} & {$[5]$} & {$[2]$} & {$[5]$} \\
\hline
\end{tabular}

Works [2, 5] should be recognized as works with the most significant statistical samples. A medium frequency of scheduled repairs of OHL $220-500 \mathrm{kV}$ in [5] vary (table 2) from 1.5 to 2.9 1/year; but in [2] it's within the range 2,8-3,1 1/year. Later works refers to much greater values: 10,0-13,2 [3] and 5,0-12,8 [1] 1/year. A medium frequency of scheduled OHL commutations is presented in [4], which equals 10,014,81 /year, i.e. sum of their switching on/off; it is clear, that frequency of OHL scheduled repairs from [4] will be twice as little, i.e 5,0-7,4 1/year. It can be assumed, that such significant spread in presented characteristics can't give an estimate of real reliability characteristics of overhead lines in terms of scheduled outages.

Only in works [2,5] there were undertaken a studies of scheduled outages of double-circuit OHL. But these works refer to period of late 1970 s - beginning of the 1980s.

Thus, authors set themselves the task of throwing light on reliability characteristics of (A)T and OHL in main electrical grids from the perspective of real values of frequency and duration of scheduled repairs.

\section{Reliability characteristics of (auto)transformers}

Monthly reports of actual carried out repairs of (A)T and OHL for a period of 2014-2016 years of Federal
Grid Company (i.e. voltage of $220-750 \mathrm{kV}$ ) of most part of regions of the country were taken as source data. Statistical sample size for $\mathrm{A}(\mathrm{T})$ is shown in table 4.

Table 4. Statistical sample size for (auto)transformers.

\begin{tabular}{|c|c|c|c|c|}
\hline \multirow{2}{*}{ Region } & \multicolumn{4}{|c|}{ Amount of (auto)transformers-years in grids, } \\
\cline { 2 - 5 } & 220 & 330 & 500 & 750 \\
\hline Central & 615 & 63 & 111 & 32 \\
\hline North-West & 213 & 291 & 6 & 16 \\
\hline $\begin{array}{c}\text { Volga } \\
\text { Region }\end{array}$ & 477 & - & 84 & - \\
\hline Urals & 471 & - & 96 & - \\
\hline Siberian & 831 & - & 243 & - \\
\hline Southern & 270 & 132 & 42 & - \\
\hline Total & 2877 & 486 & 582 & 48 \\
\hline
\end{tabular}

Classification of scheduled outages of grid elements was proposed in [6]. (A)T outages were considered by analogy with:

- for carrying out scheduled or unscheduled repairs or maintenance of (A)T (group 1);

- for carrying out scheduled or unscheduled repairs, maintenance or reconstruction of allied equipment (group 2);

Make notice that 'unscheduled repair' term was due to the fact that equipment is taken out from the service by an unscheduled dispatching form, but fundamentally it's scheduled outage. Whereby a common feature of scheduled outage is availability of certain period of time between making decision about outage and the moment of outage [6].

Number and duration of scheduled outages from table 4 is presented in table 5. As shown in table 5, scheduled outages connected with scheduled or unscheduled works on (A)T (group 1) constitute the major portion of outages $(75-90 \%)$.

Table 5. Unscheduled (auto)transformers outages data.

\begin{tabular}{|c|c|c|c|c|}
\hline \multirow{2}{*}{$\begin{array}{c}\text { Voltage, } \\
\mathrm{kV}\end{array}$} & \multicolumn{2}{|c|}{$\begin{array}{c}\text { Number of outages } \\
\text { by groups, ea }\end{array}$} & \multicolumn{2}{c|}{$\begin{array}{c}\text { Total duration of } \\
\text { outages by groups, } \\
\text { thous. hrs }\end{array}$} \\
\cline { 2 - 5 } & 1 st group & $\begin{array}{c}\text { 2nd } \\
\text { group }\end{array}$ & 1 st group & $\begin{array}{c}2 \mathrm{nd} \\
\text { group }\end{array}$ \\
\hline 220 & 5316 & 1389 & 902,8 & 124,3 \\
\hline 330 & 1026 & 159 & 187,8 & 12,9 \\
\hline 500 & 1164 & 276 & 231,4 & 30,4 \\
\hline 750 & 108 & 33 & 31,4 & 0,8 \\
\hline
\end{tabular}

There were calculated medium frequency and duration of scheduled repairs of (A) $\mathrm{T}$ according to table 5 data - see table 6 .

Annually, (A)T $220-500 \mathrm{kV}$ is scheduled taken out from the service more than twice (table 6). Thus, frequency of scheduled repairs (A)T from table 6 is close to values given in [4] about 50 years ago. But it should be noted, that actual medium durations and annual average durations of (A)T repairs turn out to be much greater than values published before. Thus, medium duration of a scheduled outage for (A)T 220 $\mathrm{kV}$ is 153 hours facing 30 hours shown in [1], for example. According to [1] failure rate of (A)T $220 \mathrm{kV}$ 
is 0,014 1/year with mean restoration time of $250 \mathrm{hrs}$. Hereof an annual average downtime of (A)T for emergency and restoration repair $0,014 \cdot 250=3,5 \mathrm{hrs} 8$, i.e. is in 100 times lesser than $357 \mathrm{hrs}$, shown in table 6.

Table 6. Reliability characteristics of (auto)transformers.

\begin{tabular}{|c|c|c|c|c|c|c|c|}
\hline \multirow{2}{*}{ Voltage, $\mathrm{kV}$} & \multicolumn{2}{|c|}{$\mu, 1 /$ year } & \multirow{2}{*}{ Total by } & \multicolumn{2}{c|}{$T_{\text {rep }}$ hrs } & \multirow{2}{*}{ Total by } & Annual average duration of \\
& 1st & 2nd & groups 1-2 & 1st & 2nd & groups 1-2 & repairs, hrs \\
\hline 220 & 1,85 & 0,48 & 2,33 & 170 & 90 & 153 & 357 \\
\hline 330 & 2,11 & 0,33 & 2,44 & 183 & 81 & 169 & 412 \\
\hline 500 & 2,00 & 0,47 & 2,47 & 199 & 110 & 182 & 450 \\
\hline 750 & 2,25 & 0,69 & 2,94 & 291 & 25 & 229 & 673 \\
\hline
\end{tabular}

\section{Reliability characteristics of overhead lines}

There were carried out a research of reliability characteristics of single circuit and double circuit overhead lines. Statistical sample size for OHL is shown in table 7 and 8.

Table 7. Statistical sample size for single circuit overhead lines.

\begin{tabular}{|c|c|c|c|c|}
\hline \multirow{2}{*}{ Region } & \multicolumn{5}{|c|}{$\begin{array}{c}\text { Number of OHL, thous. km-year/line-year in } \\
\text { grids, kV }\end{array}$} \\
\hline & 220 & 330 & 500 & 750 \\
\hline Central & $49,4 / 1083$ & $5,6 / 123$ & $32,6 / 198$ & $7,8 / 30$ \\
\hline $\begin{array}{c}\text { North- } \\
\text { West }\end{array}$ & $10,6 / 271$ & $15,2 / 255$ & - & $3 / 15$ \\
\hline $\begin{array}{c}\text { Volga } \\
\text { Region }\end{array}$ & $23,2 / 460$ & - & $16,4 / 91$ & - \\
\hline Urals & $31,5 / 659$ & - & $24,4 / 128$ & - \\
\hline Siberian & $55,0 / 1422$ & - & $45,3 / 271$ & - \\
\hline Southern & $13,4 / 313$ & $9,9 / 122$ & $12,3 / 39$ & - \\
\hline Total & $183,1 / 4208$ & $30,7 / 500$ & $131,0 / 727$ & $10,8 / 45$ \\
\hline \multicolumn{5}{|c}{} \\
\hline
\end{tabular}

There were defied following fault groups for OHL (see [6]):

- for carrying out scheduled or unscheduled repairs or maintenance of OHL (group 1);

- for carrying out scheduled or unscheduled repairs, maintenance or reconstruction of allied equipment (group 2);

- for carrying out OHL reconstruction (group 3);
- for performing

construction and installation and other works in fenced-off area of OHL on requests of outside organizations (group 4).

Table 8. Statistical sample size for double circuit transmission lines.

\begin{tabular}{|c|c|c|}
\hline \multirow{2}{*}{ Region } & $\begin{array}{c}\text { Number of OHL, thous. km-year/line-year } \\
\text { in grids, } \mathrm{kV}\end{array}$ \\
\hline & 220 & 330 \\
\hline Central & 171 & 15 \\
\hline North-West & 35 & 29 \\
\hline $\begin{array}{c}\text { Volga } \\
\text { Region }\end{array}$ & 85 & - \\
\hline Urals & 169 & - \\
\hline Siberian & 157 & - \\
\hline Southern & 35 & 6 \\
\hline Total & 652 & 50 \\
\hline
\end{tabular}

Number and duration of scheduled outages of OHL from tables 7,8 are shown in table 9,10 correspondingly.

Table 10. Data of scheduled outages of double circuit transmission lines.

\begin{tabular}{|c|c|c|c|c|}
\hline \multirow{2}{*}{$\begin{array}{c}\text { Voltage, } \\
\text { kV }\end{array}$} & \multicolumn{2}{|c|}{$\begin{array}{c}\text { Number of outages by } \\
\text { groups, ea }\end{array}$} & \multicolumn{2}{|c|}{$\begin{array}{c}\text { Total duration of } \\
\text { outages by groups, } \\
\text { thous. hrs }\end{array}$} \\
\cline { 2 - 5 } & $\begin{array}{c}\text { Single } \\
\text { circuit } \\
\text { downtime }\end{array}$ & $\begin{array}{c}\text { Double } \\
\text { circuit } \\
\text { downtime }\end{array}$ & $\begin{array}{c}\text { Single } \\
\text { circuit } \\
\text { downtime }\end{array}$ & $\begin{array}{c}\text { Double } \\
\text { circuit } \\
\text { downtime }\end{array}$ \\
\hline 220 & 3822 & 107 & 371,4 & 8,2 \\
\hline 330 & 296 & 5 & 37,3 & 0,3 \\
\hline
\end{tabular}

Table 9. Data of scheduled outages of single circuit transmission lines.

\begin{tabular}{|c|c|c|c|c|c|c|c|c|}
\hline \multirow{2}{*}{ Voltage, $\mathrm{kV}$} & \multicolumn{4}{|c|}{ Number of outages by groups, ea } & \multicolumn{3}{c|}{ Total duration of outages by groups, thous. hrs } \\
\cline { 2 - 9 } & 1 1st & 2nd & 3rd & 4 th & 1st & 2nd & 3rd & 4th \\
\hline 220 & 9344 & 1318 & 30 & 48 & 936,3 & 105,5 & 4,1 & 2,4 \\
\hline 330 & 1405 & 123 & 11 & 3 & 215,0 & 12,5 & 1 & 0,8 \\
\hline 500 & 2074 & 251 & 1 & 11 & 273,5 & 20,7 & 0,4 & 1,7 \\
\hline 750 & 101 & 32 & 0 & 0 & 18,2 & 2,9 & 0 & 0 \\
\hline
\end{tabular}

Unscheduled outages connected with works, carried out on OHL (group 1), are equal $75-80 \%$ of total number of outages. Medium frequency and duration of scheduled repairs of OHL were determined based on data from tables 7-10 - see tables 11-12.

From the table 11 following that each of OHL 220$750 \mathrm{kV}$ is taken out from the service from 2,6 to 3,2 1/year. This is a bit more than it was in 1980s: 1,5-2,9 $1 /$ year - see [5]. However, average duration of scheduled repair of OHL 220-500 kV was grown from 12-17 (see [5]) to 98-159 hrs, approximately by an order of magnitude, during the same period. According to [3] nonrecoverable failure for $\mathrm{OHL} 500 \mathrm{kV}$ is $0,3-$ 0,4 1/year for $100 \mathrm{~km}$ for mean restoration time of 
about 10 hrs. For average length of OHL $500 \mathrm{kV}$ in Russia at a level of $200 \mathrm{~km}$, its emergency and restoration downtime is $0,4(200 / 100) \cdot 10 \approx 8 \mathrm{hrs}$. Whereby annual average duration of scheduled repair of OHL $500 \mathrm{kV}$ is (table 11) 3,2.127=406 hrs, that almost 50 times higher its annual average emergency and restoration downtime.

Table 11. Reliability characteristics for single circuit overhead lines.

\begin{tabular}{|c|c|c|c|c|c|c|c|c|c|c|}
\hline \multirow{2}{*}{ Voltage, $\mathrm{kV}$} & \multicolumn{4}{|c|}{$\mu, 1 /$ year } & \multirow{2}{*}{$\begin{array}{l}\text { Total by } \\
\text { groups } 1-2\end{array}$} & \multicolumn{4}{|c|}{$T_{r e p}, \mathrm{hrs}$} & \multirow{2}{*}{$\begin{array}{l}\text { Total by } \\
\text { groups } 1-2\end{array}$} \\
\hline & $1 \mathrm{st}$ & 2nd & 3rd & 4th & & $1 \mathrm{st}$ & 2nd & 3rd & 4th & \\
\hline 220 & 2,22 & 0,31 & 0,01 & 0,04 & 2,6 & 100 & 80 & 139 & 50 & 98 \\
\hline 330 & 2,81 & 0,25 & 0,02 & 0,01 & 3,1 & 153 & 102 & 88 & 277 & 149 \\
\hline 500 & 2,84 & 0,35 & 0 & 0,02 & 3,2 & 132 & 83 & 408 & 152 & 127 \\
\hline 750 & 2,24 & 0,72 & 0 & 0 & 3,0 & 180 & 91 & 0 & 0 & 159 \\
\hline
\end{tabular}

Table 12. Reliability characteristics for single circuit overhead lines

\begin{tabular}{|c|c|c|c|c|c|}
\hline \multirow[b]{2}{*}{ Voltage, $\mathrm{kV}$} & \multicolumn{2}{|c|}{$\mu, 1 /$ year } & \multicolumn{2}{|c|}{$T_{r e p}, \mathrm{hrs}$} & \multirow{2}{*}{$\begin{array}{c}\text { Annual average duration of } \\
\text { repairs (double circuit } \\
\text { downtime), hrs }\end{array}$} \\
\hline & $\begin{array}{l}\text { Single circuit } \\
\text { downtime }\end{array}$ & $\begin{array}{c}\text { Double circuit } \\
\text { downtime }\end{array}$ & $\begin{array}{l}\text { Single circuit } \\
\text { downtime }\end{array}$ & $\begin{array}{l}\text { Double circuit } \\
\text { downtime }\end{array}$ & \\
\hline 220 & 5,8 & 0,16 & 97,2 & 76,2 & 12,1 \\
\hline 330 & 5,9 & 0,10 & 126 & 60,9 & 6,1 \\
\hline
\end{tabular}

\section{Analysis of scheduled repairs duration during a year}

Additionally there were plotted distributions of scheduled repairs duration of (A)T and OHL by year of period under review, i.e. proportions of the total number of repairs of given duration on time axis with accepted bin of $10 \mathrm{hrs}$. Obtained results are shown on fig. 1 and 2 as an example as applied to North-West region.

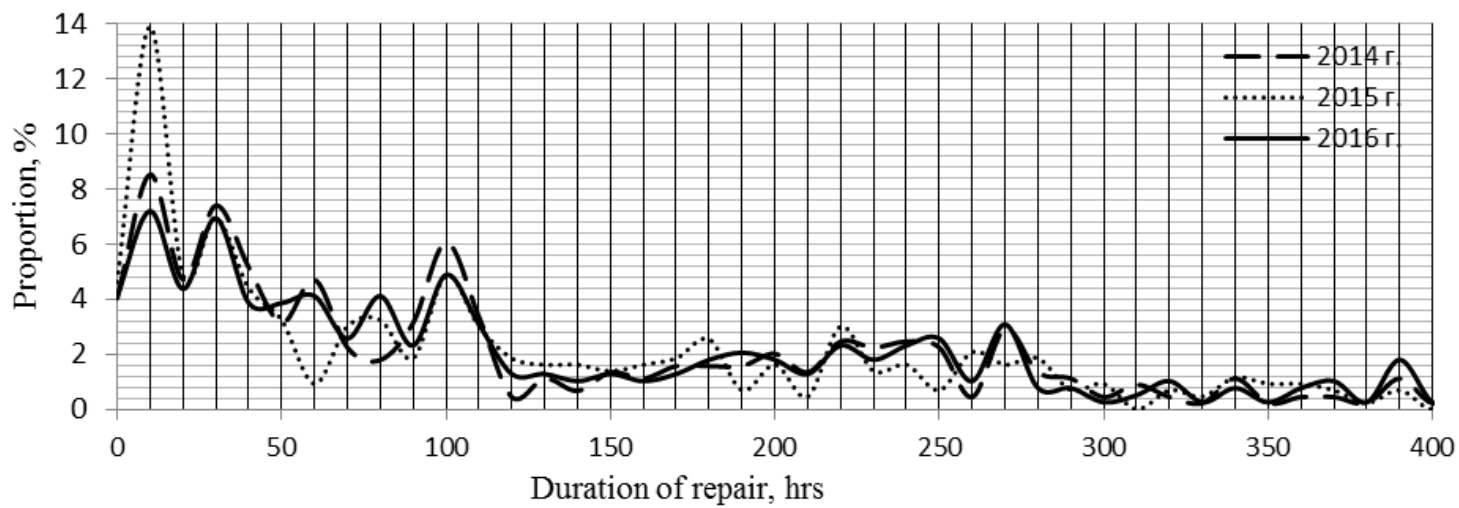

Fig. 1. Distributions of (A)T repairs by duration in North-West region.

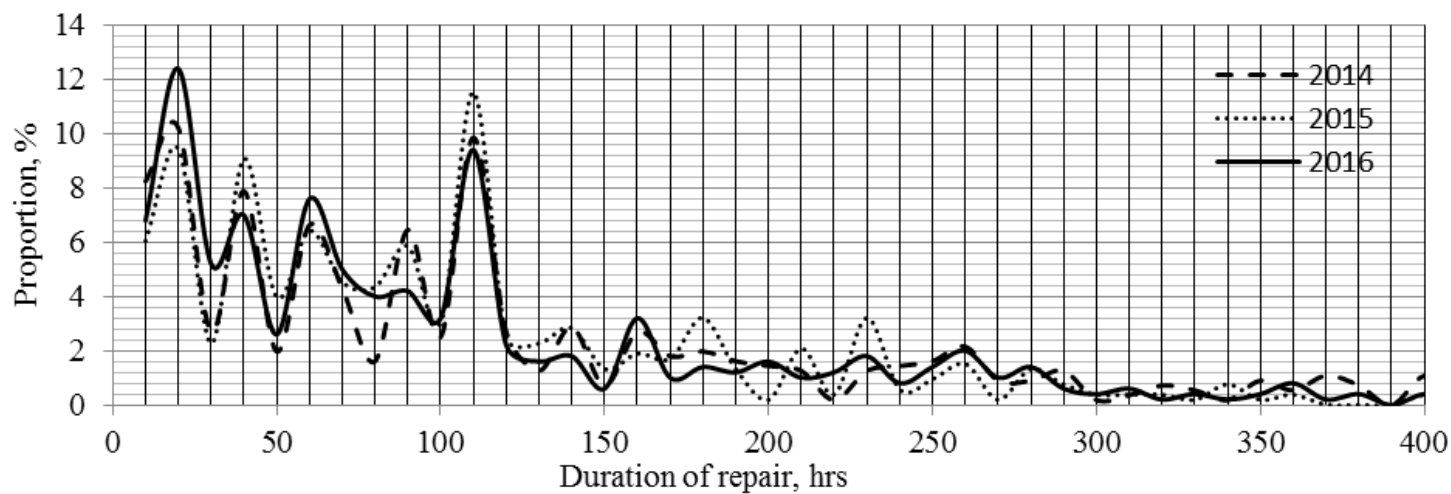

Fig. 2. Distributions of (A)T repairs by duration in North-West region.

Even visually on fig. 1 and 2 one can find similarity of distributions by year of period under review.

Additionally there was carried out correlation analysis for (A)T and OHL between regions of the country for a period of 2014-2016 yrs., where variables were: proportion of total number of outages and proportion of total duration by month without classification by voltage, i.e. relative number and duration of repairs by month. Corresponding results for OHL are shown in table 13 as an example. 
Table 13. Correlation analysis for OHL by regions.

\begin{tabular}{|c|c|c|}
\hline \multirow{2}{*}{ Compared regions } & \multicolumn{2}{|c|}{ Pearson coefficient for } \\
\cline { 2 - 3 } & $\begin{array}{c}\text { Number of } \\
\text { repairs }\end{array}$ & $\begin{array}{c}\text { Duration of } \\
\text { repairs }\end{array}$ \\
\hline Urals - North-West & 0,93 & 0,92 \\
\hline Urals - Southern & 0,89 & 0,92 \\
\hline Urals - Central & 0,89 & 0,76 \\
\hline Urals - Volga Region & 0,95 & 0,93 \\
\hline Urals - Siberian & 0,95 & 0,93 \\
\hline North-West - Southern & 0,87 & 0,89 \\
\hline North-West - Central & 0,94 & 0,78 \\
\hline North-West - Volga Region & 0,89 & 0,88 \\
\hline North-West - Siberian & 0,96 & 0,92 \\
\hline Southern - Central & 0,86 & 0,72 \\
\hline Southern - Volga Region & 0,93 & 0,88 \\
\hline Southern - Siberian & 0,88 & 0,89 \\
\hline Central - Volga Region & 0,93 & 0,68 \\
\hline Central - Siberian & 0,93 & 0,84 \\
\hline Volga Region - Siberian & 0,93 & 0,93 \\
\hline
\end{tabular}

Minimum value of Pearson coefficient $(R)$ is $R_{\min }=0,88$ for relative number of outages for comparison Southern and Siberian regions and $R_{\min }=0,68$ for relative duration of outages for comparison Central and Volga regions (table 4). It is commonly known that correlational relationship is high for $R \geq 0,7$ and very high for $R \geq 0,9$. Thus, it is to be supposed that for accepted maintenance and repair of OHLs system for a period under review a choice of a certain year of observation is not general contributing factor.

It is commonly assumed that in reliability evaluations scheduled repairs are carried out on 'summer' periods. With that a decreasing correction factor, that is approximately $K=0,5-0,6$, is introduced for calculation period. Therefore, scheduled outages from table 5 and 7 were classified by months. The result is shown on fig. 3 and 4.

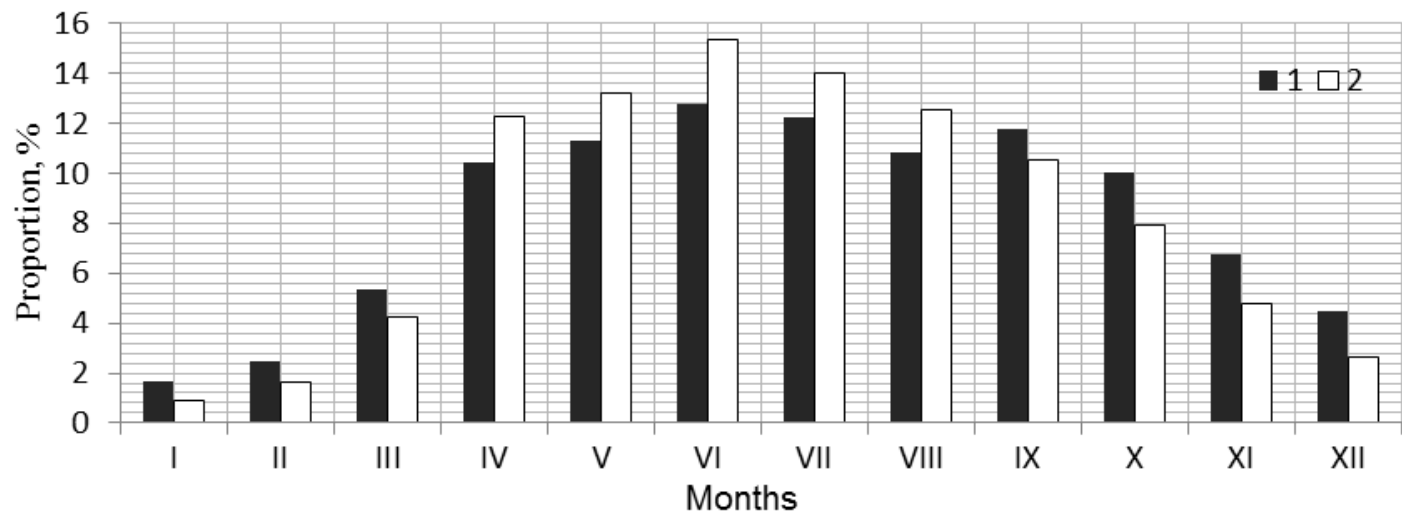

Fig, 3 Distributions of number and duration of repairs of (A)T by months: 1 - proportions of the total number of repairs; 2 proportions of the total duration of repairs.

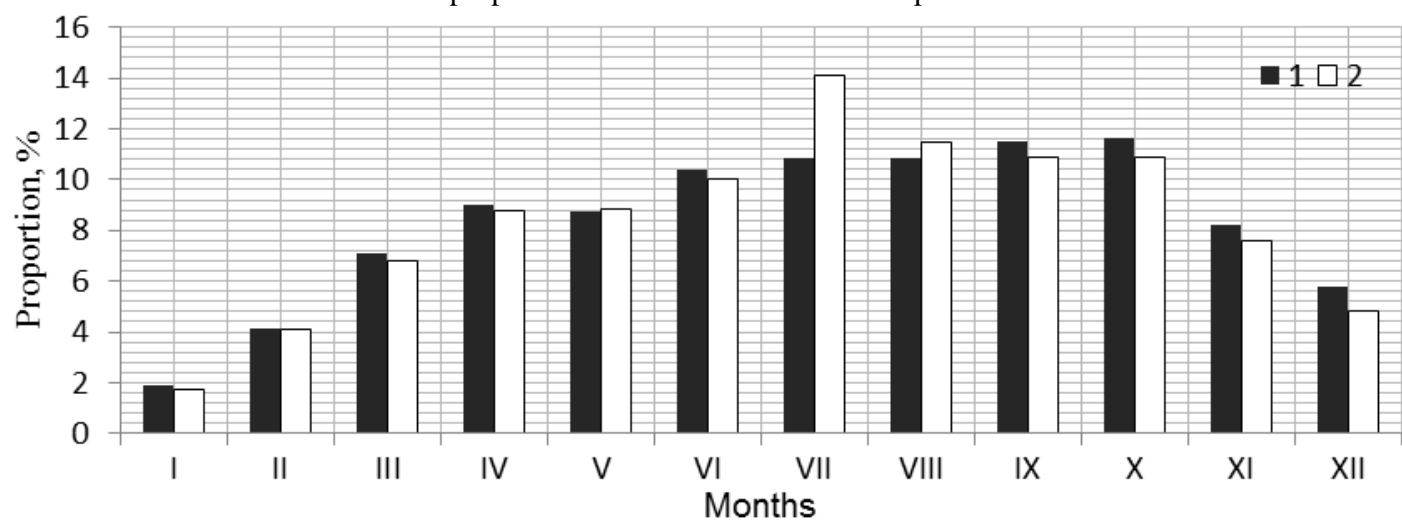

Fig, 4 Distributions of number and duration of repairs of OHL by months: 1 - proportions of the total number of repairs; 2 proportions of the total duration of repairs.

Frequency and duration of scheduled repairs are constantly increasing from March till November; in the winter period a number of scheduled repairs is lower, than in summer period, however, they shouldn't be neglected. For example, 4-6\% of annual number of repairs accrue to December, while the annual maximum is about $11-13 \%$ for both (A)T and OHL. From fig. 2 also following that histogram of total number of repairs is lower than histogram of total duration of repairs, but it's vice versa for the winter period. The reason is obvious - it's necessary to carry out more labor and time consuming repairs in warm seasons.

The maximum value of proportion of total duration of scheduled repairs of (A)T accrues to June and equals about $16 \%$, and to July for OHL (14\%). Therefore, $100 / 16=6,3$ and $100 / 14=7,1$ are minimum necessary number of months to carry out scheduled repairs of (A)T and OHL by an analogy with maximum load utilization time in a power system. 
Where $K=6,3 / 12=0,53$ for (A) $\mathrm{T}$ and $K=7,1 / 12=0,59$ for OHL, which is confirm the accepted technical practice, which is used for reliability evaluation of electric circuit schemes.

\section{Analysis of medium frequency of scheduled repairs of $\mathrm{OHL}$ dependence on their length}

\author{
Line length, $\mathrm{km}$ \\ Frequency of repairs, 1/year \\ to 100 \\ 3,0
}

As we can see, some association between frequency of repairs and length appears at line lengths above 100 $\mathrm{km}$. Thus, for OHL length above $300 \mathrm{~km}$ frequency of scheduled outages increases of 1.5 times more than

$$
\begin{array}{cc}
\text { Line length, km } & \text { to } 30 \\
\text { Frequency of repairs, 1/year } & 3,3
\end{array}
$$

Therefore, it's confirmed once more that association between OHL length and frequency of its repairs in reliability evaluations of electric circuit schemes isn't general contributing factor and could be taken into account only for extremely long lines.

\section{Conclusion}

1. According to processed representative statistical data there were obtained reliability characteristics of (A)T and OHL in main electrical grids of power systems. It's found that from the perspective of medium frequency and duration of scheduled repairs they are way below than values obtained in the last century.

2. Average duration of scheduled repairs of (A)T increased of 5 times upon the average for last 30 years and annual duration of their scheduled downtimes more than ten times. Applied in the last century normative approach to planning a periodicity of scheduled repairs of (A)T included their annual current repair and major repair once in 8-12 years. Technically, it could have been seemed more progressive than the modern approach, based on evaluation of current state of equipment, because it provided shorter periods of weakening of grid scheme during operation.

For the last 30 years average duration of scheduled repair of OHL $220-500 \mathrm{kV}$ was grown from 12-17 to 98-159 hrs, i.e. almost in ten times. Upon that the main part of scheduled outages connects with repairs or maintenance of OHL itself, but not its reconstruction or other external reasons.

These facts require to be carefully thought.

3. It is found that annual duration of scheduled
It was shown in [6] that frequency of scheduled outages has small dependence on a length of lines. This was explained for a variety of causes. In particular, when it's necessary to performance greater quantity of work it's accepted to increase a number of personnel (teams), but not duration of outage.

According to processed statistical data (table 9) there was analyzed dependence medium frequency of scheduled repairs on their duration:

$\begin{array}{ccc}100-200 & 200-300 & \text { Above } 300 \\ 3,9 & 3,7 & 4,5\end{array}$

short lines.

As for rather short OHLs $330 \mathrm{kV}$, which are located only in European part of the country - there's no association between given characteristics at all:

$\begin{array}{cccc}60-90 & 90-120 & 120-150 & 150-180 \\ 3,7 & 3,8 & 3,0 & 2,5\end{array}$

downtimes of (A)T and OHL exceed their annual duration of emergency and restoration repairs more than ten times. Thus, reduction of duration of repair conditions of electric grid elements could be significant reserve of power systems reliability improvement.

\section{References}

1. Karapetyan I.G Faibisovic D.L., Shapiro I.M. Spravochnik po proektirovaniyu elektricheskih setey [Reference book for the design of electrical networks]. Moscow, ENAS Publ., 2012. 320 p.

2. Guidance on the application of reliability characteristics of power system elements and the operation of power units with steam turbine units SPO Soyuztekhenergo Publ., 1985. 18 p. (in Russian)

3. Nepomnyaschiy V.A. Reliability of power systems equipment. ELECTRIC POWER. Transmission and Distribution, 2013, p.196.

4. Katson V.D., Nikitin O.V., Polovoy I.F., Halilov F.H. The annual number of switching lines and transformers of higher voltage classes Elektricheskie stancii [Power plants], 1970, 10, pp. 42-44. (in Russian)

5. Barg I.G., Edelman V.I. Overhead power transmission lines. Moscow, Energoatomizdat Publ., $248 \mathrm{p}$.

6. Edelman V.I., Barg I.G., Korobanov S.V., Pripuskova T.P. Statistical analysis of scheduled outages of OHL $35-500 \mathrm{kV}$. Elektricheskie stancii [Power plants], 1979, 11, pp. 49-54. (in Russian) 